\title{
Identification and control of the lateritic mineral pulp storage process
}

\begin{abstract}
The experimental identification of the pulp storage process that links the plant complex: Thickeners - Leaching, from the company Cmte. Pedro Sotto Alba of the Moa municipality, with the scoop of knowing the dynamics of the process for its better study and understanding. It explains the fundamental techniques and methods of identification as well as the input signal to excite the system. The experiments that were carried out are described, the mathematical models obtained are validated and the best parameters of the controller are simulated to optimize the control of the level of pulp in the storage tank. Finally, an economic and environmental assessment of the technical proposal is made.
\end{abstract}

Keywords: experimental identification, mathematical models, controller, pulp level
Volume 4 Issue 2 - 2018

\section{MsC Deynier Montero Góngora,' Ing \\ Dioslider Matos Cantillo, ${ }^{2}$ Leonardo \\ Rodríguez Mestre ${ }^{3}$}

'Center for Energy Studies and Advanced Technology of Moa "CEETAM", Cuba

${ }^{2}$ Electrical Engineering, Cuba

${ }^{3}$ Economy, Cuba

Correspondence: Deynier Montero Góngora, Center for Energy Studies and Advanced Technology of Moa "CEETAM", Cuba,Tel 24-604476,Email dmonterog@ismm.edu.cu

Received: December 08, 2017 | Published: March 21, 2018
Abbreviations: Cmte, commander; PSA, pedro sotto alba de moa; PID, proportional integral derivative; SBSA, pseudo random binary signals

\section{Introduction}

At present, modern control systems in a global context are a fundamental role in the development of solutions to problems or problems presented in domestic and industrial applications. The main contributions of modern control systems at industrial level contribute to technological innovation, profitability and maintainability of the processes to which it is controlled. According to Caldas et al., ${ }^{1}$ to design a control strategy that guarantees the existing demands, a mathematical model must be available that describes the dynamics of the process. This is based on the mathematical process that can be detected through a dynamic or static system; in short, that effectively controls any variable that occurs within any system using a model that represents its physical structure in communication with the controller of that process. However, this task is complex, because it must be governed by the laws that are involved in each of the processes. In this sense, the identification of dynamic systems provides a tool capable of generating methods that allow in a much simpler way, to establish mathematical models with an adequate level of accuracy. In the company Cmte. Pedro Sotto Alba de Moa, specifically in the process of storage of pulp from the leaching plant, it is important to maintain control of the level of it in the storage tank. To achieve this task, we take into account the available pulp capacity of the Thickeners plant and the one demanded by the Leaching Plant, guaranteeing a certain pulp flow balance. In the PSA Operations Manual (2007), a clear mention is made of the main variables that intervene in the pulp storage process, which covers the plant complex Thickeners - Leaching, as well as the characteristics of the process that were taken into account in the present work. The inefficiencies in the control of the level of pulp that takes place in the storage tank of the leaching plant are taken as the research problem. To solve the problem, the objective of the research is to obtain a mathematical model of the process, through the application of experimental identification techniques, which allows the optimal parameters of the system controller to be proposed.

\section{Current state of control and automation of the process}

A Supervision and Control System (Citect: Version 7.10) is installed in the plant complex Thickeners - Leaching, in Figure 1 you can see details of it. In each output of the thickeners there is a pump governed by a speed controller and in turn by a PI control, located in Programmable Automata of the Siemens family. The purpose of this control is to maintain an adequate level of mineral pulp in the leaching plant. According to the capacity demanded by this plant and the sedimentation characteristics of each thickener tank, it will be the specific flow pumped. In this way a total flow is obtained in the mineral storage tank, which is measured by leveling radar. There are also two intermediate booster pumps to help pumping due to the high viscosity of the ore.

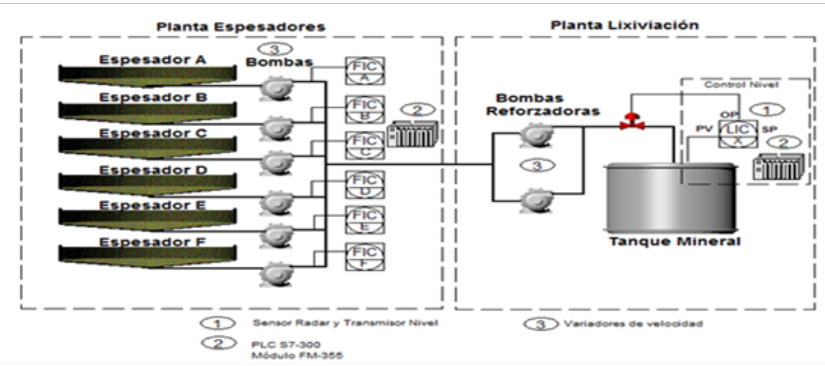

Figure I Process Supervision System Pulp Storage.

\section{Materials and methods}

It is not difficult to realize that obtaining a mathematical model that describes the process from the phenomenological point of view would be extremely complicated, since the physical-chemical processes involved would lead to differential equations systems in partial derivatives, consequently non-linear and variable over time, 
we opted for experimental identification to obtain approximate models for different points of operation Nath et al. ${ }^{2}$ In this case, for the formal mathematical modeling of this process, an experimental identification method was used, consisting in applying as excitation to the system, sequence of positive and negative steps to the flow of pulp of entrance to the storage tank, which constitute an approximation to the white noise, with special characteristics. Several experiments were performed with the SBSA, applying sequences of order 5 to the openings of the regulating valves of air flow to homes 4 and 6; variables that were added to the Citect as a result of this study. Several replicas of the sequences were also planned in order to achieve an adequate length of the input signal and the historical records corresponding to the following variables were taken: Pulp flow (Fp) and Tank level (NT). From the analysis of the steps responses prior to the system, a time constant of 7 minutes (NT) was estimated. Hence the decision to use a sampling period of measured signals of 3 seconds. For the identification process, the data was pre-processed. This consisted of suppressing the constant levels and making the average of them is zero. Then the filtering was done following the recommendations of Añez \& Scarano. ${ }^{3}$ A group of data was selected to estimate the model and another part to validate it. Simple input and simple output models were determined in correspondence by the proposal by Estrada et al., ${ }^{4}$ with structures Output Error (OE), Box Jenkins (BJ), Auto Regressive with exogenous input (ARX), for different orders. The models were transformed into transfer functions, which are easier to associate with a real plant. To process the data, the Identification Toolbox of the MATLAB professional package Ljung ${ }^{5}$ was used, which contains tools for obtaining mathematical models of dynamic systems based on the observed input-output data. The following describes the performance of one of the experiments carried out: 667 data were taken corresponding to the variables (NT and Fp). In this case, the variable speed drives experienced a variation of 20 to $99 \%$ of their total travel. Figure 2 shows the measurements of the input and output variables.

For NT, the best model BJ22221 was obtained with an adjustment of $78.67 \%$, which is a model of order 2 .

$$
\frac{N T(s)}{F p(s)}=\frac{2.941 * 10^{-5} s+1.305 * 10^{-6}}{s^{2}+0.01049 s+7.393 * 10^{-7}}
$$
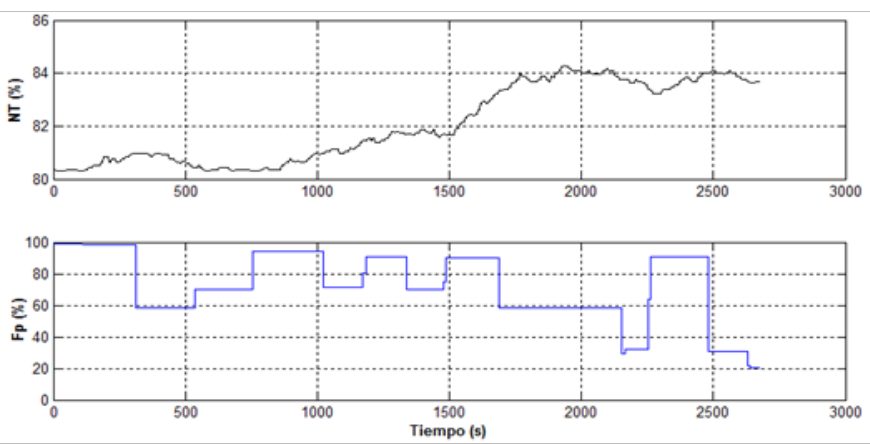

Figure 2 Input data \& output of experiment \# I.

With respect to the validation of the models, residue analysis (prediction errors) was carried out, taking into account that certain assumptions were made with respect to noise Ljung \& Guo. ${ }^{5}$ Figure 3 show that, the function of correlation of the residues is within the levels of confidence and the function of cross-correlation between the residues and the input, reflects its independence, since it does not leave the reliability intervals. For the validation of the model, the comparison of the output of the model with the real output was made, which is shown in Figure 4, where it is observed that the output of the model is quite close to the real one. Regarding the configuration of the zeros and poles of this model, its stability is evidenced by the fact that the two poles are located in the left half plane of the complex plane (Figure 5).
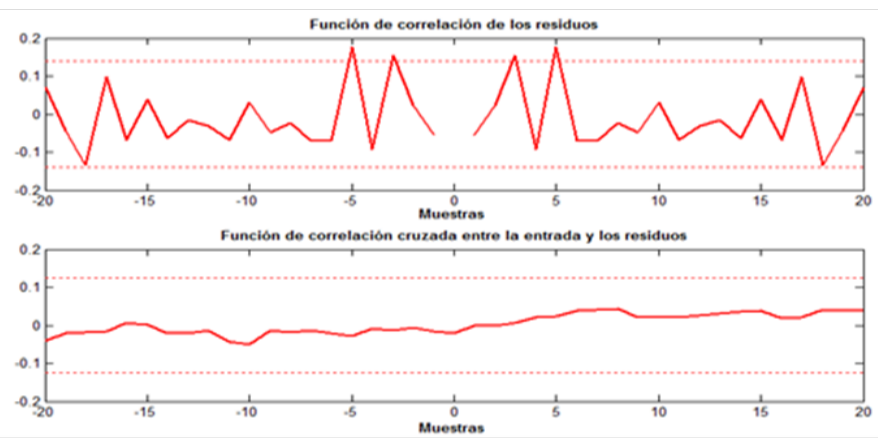

Figure 3 Residue test for the estimated model bj 2222I.

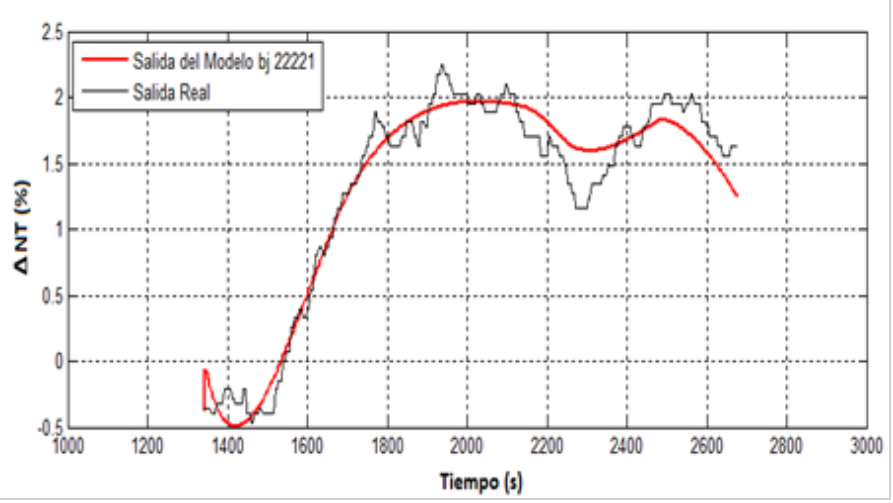

Figure 4 Real Output minus Output of the Simulated Model bj 2222I.

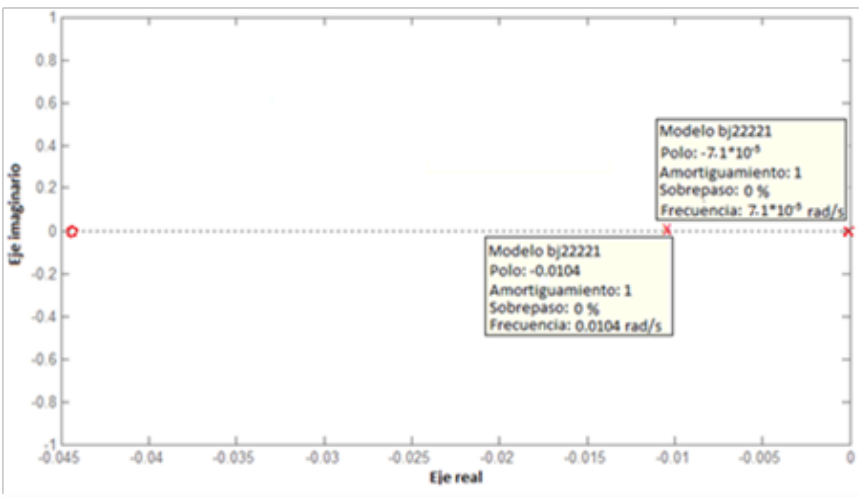

Figure 5 Map of poles and zeros of model bj 2222I.

\section{Driver adjustment}

To find the best tuning of the closed loop controllers, the PID Tuner graphic interface, invoked by the pidtool command from the Command Windows of the MATLAB, was used. For the simulation (Figure 6), a comparison between different configurations of the controllers adapted to the pulp level control loop in the tank was taken 
into account, which allowed selecting the most suitable configuration. As shown in Figure 7, the blue curve that represents the response of the plant in closed loop for a unit step input, exhibits a steady-state error of 0.36 , which differs greatly from the unit step input in magnitude. Analytically we can corroborate it by means of the expression:

$$
e_{s s}=\lim _{S \rightarrow 0} s^{*} \frac{1}{1+G(s) H(s)} * F p(s)
$$
is:

Substituting Fp (s) for a unit step and G (s) H (s) for model bj22221

$$
e_{s s}=s^{*} \frac{1}{1+\lim _{s \rightarrow 0}} \frac{2.941 * 10^{-5} s+1.305 * 10^{-6}}{s} * \frac{1}{s}
$$

Reducing and calculating $e_{s s}=0.3616$

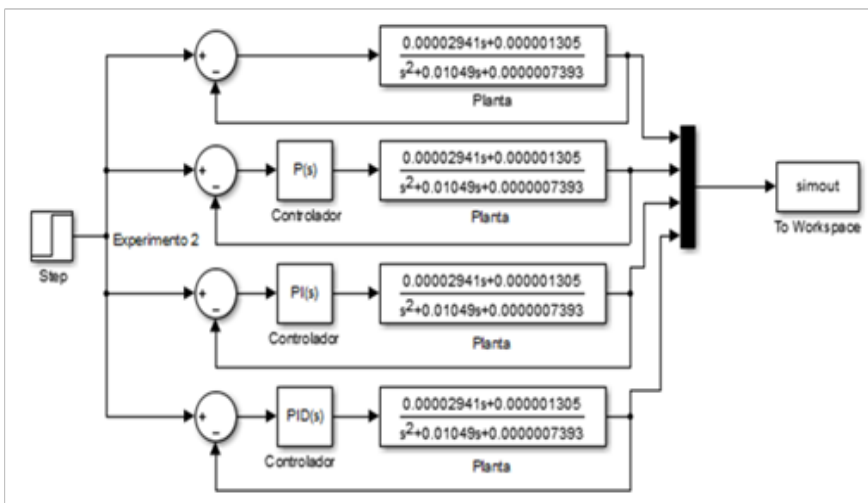

Figure 6 Simulation in the Matlab Simulink for different control configurations.

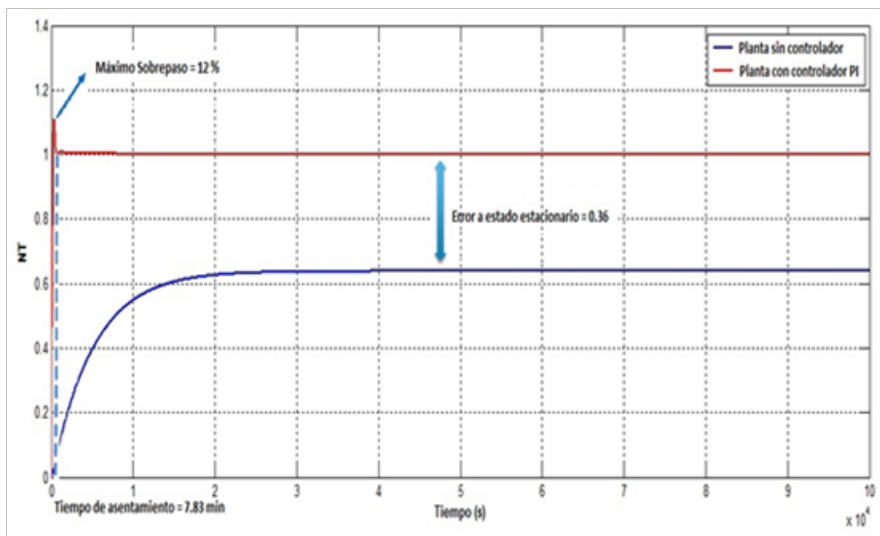

Figure 7 Pulp level for two control configurations.

\section{Results and discussion}

From the simulation of the controllers for the pulp storage process (Figure 8), it is estimated that the proposed controller has a settling time of $7.83 \mathrm{~min}$ and a surpass of $12 \%$, which is lower than the current controller's performance. $11.83 \mathrm{~min}$ and $22 \%$ (Figure 9). The consultation with technologists and plant operators allowed us to assume that approximately in a normal day of operation, the control of the pulp storage process is moved from automatic to manual 2 times. In this way, the economic benefit is presented from the point of view of the power consumption of the three-phase motor installed in the Thickeners plant, which is governed by the variable speed drive, to maintain the level of pulp in the tank. When the process switches from manual to automatic; the response of the level in closed loop with both controllers, allows estimating an economic saving through the behavior of the transitory regimes. It is determined that for 11.83 minutes, the engine presents the following data as average ( $\mathrm{In}=54.6$ $\mathrm{A}, \mathrm{Vac}=312.8 \mathrm{~V}, \cos \alpha=0.58$ ). The active power is then calculated as:

$$
P=\sqrt{3} * V * I * \cos \alpha
$$

Resulting, $P=17.2 \mathrm{~kW}$

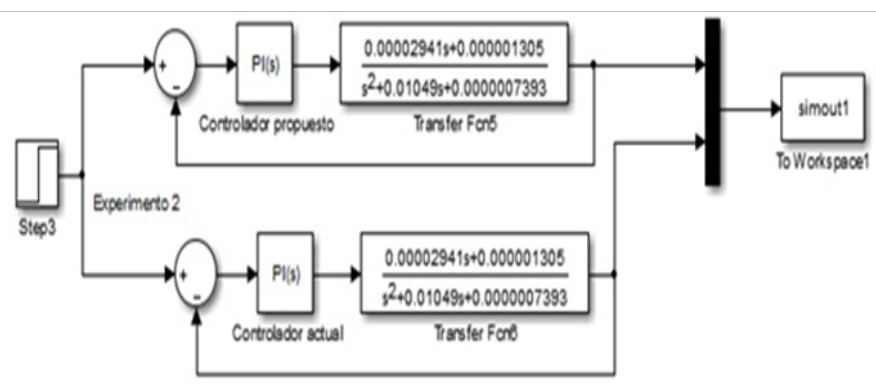

Figure 8 Simulation in the Matlab Simulink to compare two controller.

Figure 9 with the proposal of the new parameters for the PI controller, the transient time is reduced to $7.83 \mathrm{~min}$, and consequently the power consumption is reduced to $11.38 \mathrm{~kW}$. After the subtraction of both consumptions, a saving of $5.82 \mathrm{~kW}$ is evidenced, which represents once a day and to complete the daily analysis, this value is multiplied by 2 , resulting in $11.63 \mathrm{~kW}$. This allows determining that for a year with 365 days, a total of $4245.48 \mathrm{~kW}$ is saved. When establishing an economic consumption in freely convertible currency (CUC), the company Cmte. Pedro Sotto Alba has an equivalent of 200 CUC for $1000 \mathrm{~kW}$, then for an annual consumption of $4245.48 \mathrm{~kW}$; a saving of 849 CUC is reported. In order to evaluate the expenses related to the adjustment and implementation of the technical proposal, an approximate time of 3 days is estimated with the use of 2 workers. Table 1 shows the breakdown by workers according to their category.

The cost of the total investment is determined by the expression

$$
\begin{gathered}
c_{i n v}=c_{t s a l} \\
c_{i n v}=26.19 C U C
\end{gathered}
$$

\section{Recovery time of the investment}

The recovery time of the investment is given by the relationship between the investment made and the energy saved.

$$
\begin{aligned}
& T=\frac{26.19 C U C}{849 C U C}=0.03 \text { years } \\
& T=\frac{26.19 C U C}{849 C U C}=0.03 \text { years }
\end{aligned}
$$

The time in which the investment is recovered is approximately 36 days and with the savings levels the investment becomes feasible. Once the configuration of the new parameters of the PI controller has been implemented, the binding objects of the plant complex will be operated more efficiently: Thickeners - Leaching and can reduce the faults that due to overflow of the tank, cause pulp spillage at the environment. 


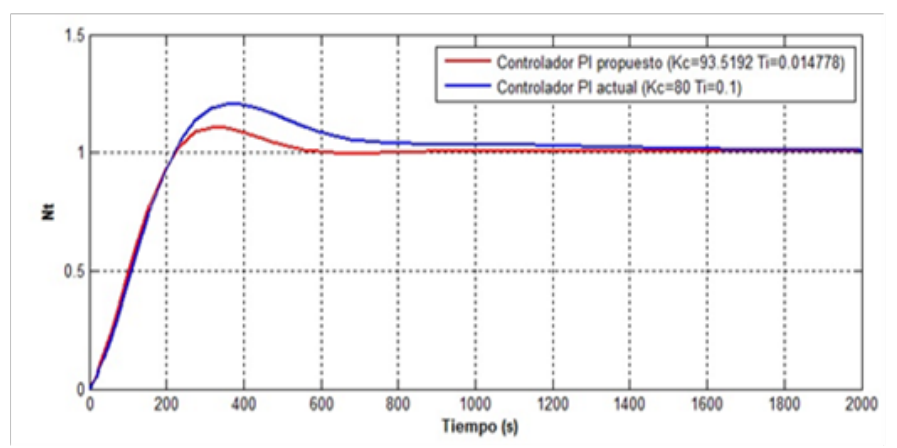

Figure 9 Pulp level using two controller.

Table I Salary expenses

\begin{tabular}{llll}
\hline Description & Quantity & $\begin{array}{l}\text { Daily cost } \\
\text { (CUC) }\end{array}$ & Total cost (CUC) \\
\hline Advanced technician & $\mathrm{I}$ & 5 & $\mathrm{I} 5$ \\
Average technician & $\mathrm{I}$ & 3.73 & $\mathrm{II} .19$ \\
Total cost of salary & & & 26.19 \\
\hline
\end{tabular}

\section{Conclusion}

The pulp storage process was characterized and the main variables were determined from its analysis as an automatic regulation object. The approximate models were obtained on the basis of the experimental identification that relates the level of the storage tank with the flow of pulp manipulated by the speed variators of the motors installed in the suction pumps of the Thickeners plant. Validation of the obtained mathematical model, Bj 22221, was carried out, which provided an adjustment of $78 \%$, showing an acceptable behavior of the residues. The values of the PI controller that best simulated the real behavior of the process were proposed $(\mathrm{Kc}=93.5192$ and $\mathrm{Ti}=0.014778)$. With the implementation of the new parameters of the process controller, an energy saving per year of 849 CUC is reported for the use of the three-phase motor governed by the variable speed drive. This gives a 36 day payback time.

\section{Acknowledgements}

My Institute Superior Miner Metallurgical de Moa "DrC Antonio Núñez Jiménez") representative is fully aware of this submission.

\section{Conflict of interest}

The author declares there is no conflict of interest.

\section{References}

1. Caldas or, Jiménez S, Mejía E, et al. Parametric identification in closed loop of pneumatic drive system for double acting cylinder. Faculty of Engineering Magazine; UPTC, 2012;21(33):9-19.

2. Nath N, chakrabortiand n, Shekhar R. Reduction of Indian nickeliferrous ore in a fixed bed reactor with gas flowing vertically through the bed. Scandinavian Journal of Metallurgy. 1998;27(1):14-22.

3. Añez G, Scarano M. Experimental modeling of the level of a water tank in a pilot plant. Telematique 2015;14(1):58-78.

4. Estrada I, Peña J, Guarnizo C. Estimation of linear models for the predictive control of small hydroelectric plants. Magazine Postgraduate Solutions EIA; 2012;(9):63-78.

5. Ljung L. System Identification Toolbox. User's Guide. New Jersey: Prentice-Hall, editor. Manual of Operations of the "Leaching" Plant of the company "Cmte.Pedro Sotto Alba; 2012. 